\title{
PENGARUH KETERLIBATAN KERJA TERHADAP KEPUASAN KERJA DAN KINERJA PEGAWAI
}

(Studi pada Perwakilan Badan Kependudukan dam Keluarga Berencana Nasional Provinsi Kalimantan Tengah)

\author{
Obi Seprianto \\ Fakultas Ekonomi dan Bisnis \\ Universitas Palangka Raya, Indonesia \\ e-mail: obyseprianto71@gmail.com
}

\begin{abstract}
Abstrak
Tujuan - Penelitian ini bertujuan untuk menguji dan menganalisis secara empiris pengaruh keterlibatan kerja terhadap kepuasan kerja dan kinerja pegawai

Desain/Metodelogi/Pendekatan - Metode penelitian yang digunakan kuantitatif. Sampel dalam penelitian ini terdiri dari 127 pegawai Perwakilan Badan Kependudukan dan Keluarga Berencana Nasional Provinsi Kalimantan Tengah. Penentuan sampel menggunakan teknik proportional sampling. Proses analisis data menggunakan bantuan SmartPLS 3.3.2

Hasil Penelitian - menunjukkan bahwa Keterlibatan Kerja berpengaruh positif dan signifikan terhadap kepuasan kerja dan kinerja pegawai di BKKBN Provinsi Kalimantan Tengah.
\end{abstract}

Kata kunci: Keterlibatan Kerja, Kepuasan Kerja dan Kinerja Pegawai

\section{Effect Of Job Involvement On Job Satisfaction And Employee Performance}

\section{(Studies on Representatives of the National Population and Family Planning Board of Central Kalimantan Province)}

\begin{abstract}
Purpose - This study aims to test and empirically analyze the effect of job involvement on job satisfaction and employee performance

Design/methodology/approach - The research method used is quantitative. The sample in this study consisted of 127 employees of representatives of the National Population and Family Planning Agency of Central Kalimantan Province. Determination of the sample using proportional sampling technique. The data analysis process uses the help of SmartPLS 3.3.2

Findings - shows that Job Involvement has a positive and significant effect on job satisfaction and employee performance in the BKKBN of Central Kalimantan Province.
\end{abstract}

Keywords: : Job Involvement, Job Satisfaction and Employee Performance 


\section{PENDAHULUAN}

Dalam kehidupan sehari-hari manusia tidaklah lepas dari berbagai organisasi, karena manusia merupakan makhluk sosial yang cenderung untuk selalu hidup bermasyarakat. Sebagian besar waktu manusia dihabiskan baik sebagai anggota dari organisasi kerja, sekolah, sosial, negara, dan lain sebagainya. Di era sekarang ini, organisasi bukan hanya berfokus kepada kebijakan dan prosedur saja, tetapi organisasi dibentuk oleh manusia dan hubungannya satu dengan yang lain. . Kinerja suatu organisasi juga dikatakan berhasil dalam mencapai tujuannya dapat di pengaruhi oleh faktor dari dalam organisasi seperti keterlibatan kerja dan kepuasan kerja pegawai di dalam pekerjaannya.

Keterlibatan kerja merupakan faktor yang bisa mempengaruhi kinerja. Menurut Robbins dan Judge (2012) keterlibatan kerja diartikan sebagai suatu ukuran sampai dimana individu secara psikologis memihak pekerjaan mereka dan menganggap penting tingkat kinerja yang dicapai sebagai penghargaan diri. Keterlibatan kerja mempunyai konsekuensi terhadap hasil kerja, yang diantaranya adalah kinerja. Oleh karena itu dengan semakin terlibat dalam suatu pekerjaan, pegawai diharapkan dapat menghasilkan kinerja yang lebih baik karena individu dengan tingkat keterlibatan yang tinggi pada pekerjaannya akan memandang bahwa pekerjaan mereka merupakan bagian dari kehidupan mereka. Begitupun terhadap kepuasan kerja sebagai sikap umum terhadap pekerjaan seseorang, seperti perasaan senang atau gembira, atau perasaan suka seseorang sebelum dan setelah melakukan suatu pekerjaan. Tentunya semakin pegawai terlibat akan semakin meningkatkan tingkat kepuasan pegawai (Yakup : 2017).

Berdasarkan observasi awal yang dilakukan peneliti berkaitan dengan keterlibatan kerja seperti terdapat ASN yang kurang terlibat di dalam pekerjaannya sendiri hal tersebut ditunjukan dengan adanya ASN yang tidak sesuai dengan jadwal dalam hal menyelesaikan pekerjaan yang telah ditetapkan. Hal tersebut disebabkan oleh kelalaian pegawai untuk menyelesaikan pekerjaan tersebut ditunjukan dengan adanya ASN yang bermain game dan ngobrol saat jam kerja berlangsung. Tentunya fenomenan ini sangat berdampak kepada kinerja pegawai, dan tentunya berpengaruh terhadap kepuasan kerja secara psikologi yaitu yang berkaitan dengan keterampilan dan sikap terhadap kerja serta terhadap sosial dapat menyebabkan hubungan antar ASN menjadi renggang/ tidak terjalinnya ikatan emosional yang lebih dekat karena pekerjaan tidak selesai tepat sesuai jadwal menyebabkan terjadi penumpukan pekerjaan.

Berdasarkan pada latar belakang yang telah diuraikan sebelumnya maka rumusan masalah pertama dalam penelitian ini adalah apakah keterlibatan kerja berpengaruh terhadap kepuasan kerja; apakah keterlibatan kerja berpengaruh terhadap kinerja pegawai di Perwakilan Badan Kependudukan dan Keluarga Berencana Nasional Provinsi Kalimantan Tengah.

Penelitian ini diharapkan dapat menambah wawasan, menjadi pengalaman bagi penulis, memperluas wawasan tentang teori manajemen sumber daya manusia. sebagai bahan pertimbangan atau acuan kepada Perwakilan Badan Kependudukan dan Keluarga Berencana Nasional (BKKBN) Provinsi Kalimantan Tengah dalam meningkatkan kepuasan kerja dan kinerja pegawi melalui keterlibatan kerja. 


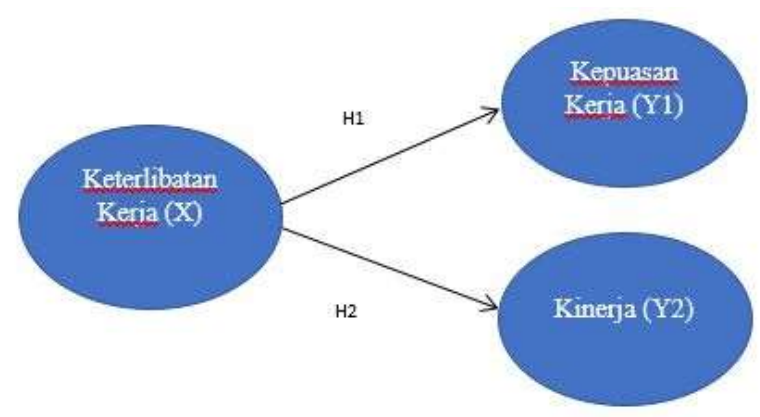

Gambar 1. Kerangka Konseptual

Berdasarkan kerangka berpikir diatas, maka penulis mengajukan hipotesis sebagai Berikut :

H1 : Keterlibatan kerja berpengaruh positif dan signifikan terhadap kepuasan kerja H2 : Keterlibatan kerja berpengaruh positif dan signifikan terhadap kinerja pegawai

\section{METODE PENELITIAN}

Perwakilan Badan Kependudukan dan Keluarga Berencana Nasional Provinsi Kalimantan Tengah yaitu, di Jl. Tjilik Riwut No.Km. 3, Bukit Tunggal, Kec. Jekan Raya, Kota Palangka Raya, Kalimantan Tengah 74874. Populasi dalam penelitian ini adalah seluruh PNS pada Perwakilan BKKBN Provinsi Kalimantan Tengah yang berjumlah 200 orang. Sampel dalam penelitian ini adalah 127 pegawai berdasarkan tabel yang di buat Isaac dan Michael dengan tingkat kesalahan yang ditetapkan 5\% dari jumlah populasi 200. Teknik sampling yang digunakan dalam dalam penelitian ini adalah proportional sampling. Variabel dan indikator yang digunakan dalam penelitian ini dapat dilihat dalam tabel berikut ini :

Tabel 1. Identifikasi Variabel

\begin{tabular}{|c|c|c|c|}
\hline No & Variabel & Definisi & Indikator \\
\hline \multirow[t]{4}{*}{1} & \multirow{4}{*}{$\begin{array}{l}\text { Keterlibatan kerja } \\
(\mathrm{X}) \\
\text { Robbins }(2010: 34)\end{array}$} & \multirow{4}{*}{$\begin{array}{l}\text { Keterlibatan kerja adalah } \\
\text { derajat dimana orang } \\
\text { dikenal dari pekerjaannya, } \\
\text { berpartisipasi aktif di } \\
\text { dalamnya, dan menganggap } \\
\text { prestasinya penting untuk } \\
\text { harga diri }\end{array}$} & 1. Respon untuk bekerja \\
\hline & & & $\begin{array}{l}\text { 2. Perilaku melibatkan diri dalam } \\
\text { pekerjaan }\end{array}$ \\
\hline & & & $\begin{array}{l}\text { 3. Rasa bertanggung jawab } \\
\text { terhadap pekerjaan }\end{array}$ \\
\hline & & & $\begin{array}{l}\text { 4. Perasaan tentang pekerjaan } \\
\text { yang belum terselesaikan dan } \\
\text { absensi. }\end{array}$ \\
\hline \multirow[t]{5}{*}{2} & \multirow{5}{*}{$\begin{array}{l}\text { Kepuasan Kerja } \\
\text { (Y1) } \\
\text { Sutrisno (2019:74) }\end{array}$} & \multirow{5}{*}{$\begin{array}{l}\text { Kepuasan kerja adalah } \\
\text { sebagai suatu reaksi } \\
\text { emosional yang kompleks. } \\
\text { Reaksi emosional ini } \\
\text { merupakan akibat dari } \\
\text { dorongan, keinginan, } \\
\text { tuntutan, dan harapan }\end{array}$} & $\begin{array}{l}\text { 1. Pekerjaan itu sendiri (The Work } \\
\text { it self) }\end{array}$ \\
\hline & & & 2. Gaji dan imbalan \\
\hline & & & 3. Kesempatan promosi \\
\hline & & & 4. Pengawasan (Supervisi) \\
\hline & & & 5. Rekan Kerja \\
\hline
\end{tabular}




\begin{tabular}{|c|c|c|c|}
\hline No & Variabel & Definisi & Indikator \\
\hline \multirow[t]{6}{*}{3} & Kinerja (Y2) & \multirow{6}{*}{$\begin{array}{l}\text { Kinerja adalah sebagai } \\
\text { proses mapun hasil } \\
\text { pekerjaan atau suatu proses } \\
\text { tentang bagaimana } \\
\text { pekerjaan berlangsung } \\
\text { untuk mencapai hasil kerja. } \\
\text { Namun, hasil pekerjaan itu } \\
\text { sendiri juga menunjukan } \\
\text { kinerja. }\end{array}$} & 1. Kuantitas (Quantity of Work) \\
\hline & Wibowo (2017) & & \\
\hline & & & 2. Kualitas (Quality of Work) \\
\hline & & & 3. Ketepatan Waktu \\
\hline & & & 4. Kehadiran \\
\hline & & & 5. Kemampuan Bekerja Sama \\
\hline
\end{tabular}

Proses pengumpulan data dalam penelitian ini dilakukan dengan menggunakan teknik penyebaran kuesioner dan dokumentasi. Sedangkan untuk skala pengukuran dalam penelitian ini menggunakan Skala Likert dengan skor skala 1-5. Bentuk jawaban skala Likert yaitu : sangat tidak setuju, tidak setuju, netral/ragu-ragu, setuju dan sangat setuju.

Data dianalisis dengan menggunakan metode Partial Least Square (PLS) dan menggunakan tools SmartPLS. PLS adalah salah satu metode alternatif SEM (structural equation modeling) yang digunakan untuk mengatasi permasalahan hubungan antar variabel, jumlah sampel tidak harus banyak dan tidak memerlukan banyak asumsi. Pada penelitian ini, peneliti menggunakan metode penelitian kuantitatif. Kuantitatif adalah data yang berbentuk angka, atau data kuantitatif yang diangkakan (scoring) sehingga mempermudah dalam menganalisis dan menyimpulkan jawaban dari rumusan masalah dan jenis deskriptif yaitu membuat deskripsi, gambar secara faktual, sistematis dan akaurat mengenai data yang diperoleh dan diolah.

Dalam metode PLS (Partial Least Square) teknik analisa yang dilakukan adalah sebagai berikut:

a. Analisa Model Pengukuran (Outer Model)

Analisa outer model juga dilakukan untuk memastikan bahwa measurement yang digunakan layak untuk dijadikan pengukuran (valid dan reliabel).

b. Uji Validitas

Menurut Ghozali \& Latan (2015) uji validitas adalah digunakan untuk mengukur sah atau valid tidaknya suatu kuesioner. Tahapan uji validitas yaitu terdiri dari dua, yaitu validitas konvergen mempunyai makna bahwa seperangkat indikator mewakili satu variabel laten dan yang mendasari variabel laten tersebut. Menguji convergent validity menggunakan nilai outer loadings atau loading factor dan nilai AVE, dan validitas diskriminan berhubungan dengan prinsip bahwa pengukur konstruk yang berbeda seharusnya tidak berkorelasi tinggi. Cara menguji validitas diskriminan dengan indikator reflektif adalah dengan melihat nilai cross loading dan fornell larcker criterion.

c. Uji Reliabilitas

Menurut Latan dan Temalagi ( 2013:46) uji reliabilitas adalah alat untuk mengukur akurasi, ketepatan dan konsistensi kuesioner dalam mengukur variabel. Untuk pengujian reliabilitas pada model SEM-PLS sendiri menggunakan rumus Cronbach Alpha dan Composite Reliability Untuk dapat dikatakan suatu konstruk reliabel, maka nilai Cronbach Alpha harus $>0,6$ dan nilai Composite Reliability harus $>0,7$.

d. Model Struktural (Inner Model)

Inner model atau model struktural pada prinsipnya digunakan untuk menguji pengaruh antara satu variabel laten dengan variabel laten lainnya. Model struktural atau inner model akan dievaluasi dengan melihat persentase variance yang dijelaskan yaitu dengan melihat 
nilai R-square (R2) untuk konstruk laten dependen, Q - Square predictive rellavancen dan VIF (Variance Inflation Factor).

e. Uji Hipotesis (Resampling bootstrapping)

Pengujian hipotesis adalah untuk mengetahui apakah variabel keterlibatan kerja (X) berpengaruh signifikan terhadap variable kepuasan kerja (Y1). Dan mengetahui apakah keterlibatan kerja (X) berpengaruh signifikan terhadap variable kepuasan kerja (Y2). Pengujian hipotesis dalam penelitian ini menggunakan model persamaan struktural Smart PLS 3.3.2. Untuk pengujian hipotesis tingkat kepercayaan yang digunakan adalah $95 \%$, maka untuk alpha ( $\alpha$ ) 5\%. Menghasilkan nilai t- tabel sebesar 1,657 .

\section{HASIL PENELITIAN}

Setelah pengumpulan data dengan mengunakan kuesioner yang disebarkan kepada responden yakni seluruh pengunjung yang datang ke restoran yang berjumlah 119 orang. Informasi tentang karakteristik responden dapat dilihat pada Tabel 2. berikut ini:

Tabel 2. Karakteristik Responden

\begin{tabular}{|c|c|c|}
\hline Karakteristik & Jumlah & Presentase $(\%)$ \\
\hline \multicolumn{3}{|l|}{ Berdasarkan Jenis Kelamin } \\
\hline Laki-laki & 65 & $51,2 \%$ \\
\hline Perempuan & 62 & $48,8 \%$ \\
\hline Total & 127 & $100 \%$ \\
\hline \multicolumn{3}{|l|}{ Usia } \\
\hline$\leq 25$ tahun & 1 & $0,8 \%$ \\
\hline $26-30$ Tahun & 9 & $7,1 \%$ \\
\hline $31-35$ Tahun & 17 & $13,4 \%$ \\
\hline $36-40$ Tahun & 35 & $27,5 \%$ \\
\hline $41-45$ Tahun & 22 & $17,3 \%$ \\
\hline $46-50$ Tahun & 11 & $8,7 \%$ \\
\hline$\geq 51$ Tahun & 32 & $25,2 \%$ \\
\hline Total & 127 & $100 \%$ \\
\hline \multicolumn{3}{|l|}{ Lama Bekerja } \\
\hline$\leq 1$ Tahun & 0 & \\
\hline $2-5$ Tahun & 10 & $7,9 \%$ \\
\hline $6-10$ Tahun & 28 & $22 \%$ \\
\hline $11-15$ Tahun & 51 & $40,2 \%$ \\
\hline $16-20$ Tahun & 1 & $0,8 \%$ \\
\hline $21-25$ Tahun & 4 & $3,1 \%$ \\
\hline$\geq 26$ Tahun & 33 & $26 \%$ \\
\hline Total & 127 & $100 \%$ \\
\hline \multicolumn{3}{|l|}{ Pendidikan Terakhir } \\
\hline SMP & 1 & $0,8 \%$ \\
\hline SMA & 31 & $24,4 \%$ \\
\hline DIPLOMA & 5 & $3,9 \%$ \\
\hline S1 & 82 & $64,6 \%$ \\
\hline $\mathrm{S} 2 / \mathrm{S} 3$ & 8 & $6,3 \%$ \\
\hline Total & 127 & $100 \%$ \\
\hline
\end{tabular}

Sumber: Data primer diolah, 202 
Tabel diatas menunjukan responden yang berjenis kelamin laki-laki 65 orang dengan presentase $51,2 \%$ dari total keseluruhan sampel, sedangkan 62 orang orang merupakan pegawai yang berjenis kelamin perempuan dengan presentase $48,8 \%$ dari total sampel. Responden yang berusia $\leq 25$ tahun sebanyak 1 orang dengan presentase $0,8 \%$ dari total sampel, berusia 26 - 30 tahun sebanyak 9 orang dengan presentase $7,1 \%$ dari total sampel, berusia 31 - 35 tahun sebanyak 17 orang dengan presentase $13 \%$ dari total sampel, beusia 36 - 40 tahun sebanyak 35 orang dengan presentase $27,5 \%$ dari total sampel, berusia 41 - 45 tahun sebanyak 22 orang dengan presentase 17,3\% dari total sampel, berusia $46-50$ tahun sebanyak 11 orang dengan presentase $8,7 \%$ dari total sampel dan berusia $\geq 51$ tahun sebanyak 32 orang dengan presentase $25,2 \%$ dari total sampel. Berdasarkan lama bekerja 2-5 tahun sebanyak 10 orang dengan presentase 7,9\% dari total sampel, lama bekerja 6-10 tahun sebanyak 28 orang dengan presentase $22 \%$ dari total sampel, lama bekerja 11-15 tahun sebanyak 51 orang dengan presentase $40,2 \%$ dari total sampel, lama bekerja 16-20 tahun sebanyak 1 orang dengan presentase $0,8 \%$ dari total sampel, lama bekerja21-25 tahun sebanyak 4 orang dengan presentase 3,1\% dari total sampel dan lama bekera $>26$ tahun sebanyak 33 orang dengan presentase $26 \%$ dari total sampel. Dan berdasarkan Pendidikan terakhir SMP Sebanyak 1 orang dengan presentase $0,8 \%$ dari total sampel, SMA sebanyak 31 orang dengan presentase $24,4 \%$ dari total sampel, Strata 1 (S-1) Sebanyak 82 orang dengan presentase $64,6 \%$ dari total sampel, dan $\mathrm{S} 2 / \mathrm{S} 3$ sebanyak 8 orang dengan presentase $6,3 \%$ dari total sampel.

\section{Hasil Penelitian Other Model}

Model pengukuran yang dilakukan menggunakan tabulasi data kuesioner menghasilkan hasil, dapat dilihat pada gambar 1 berikut :

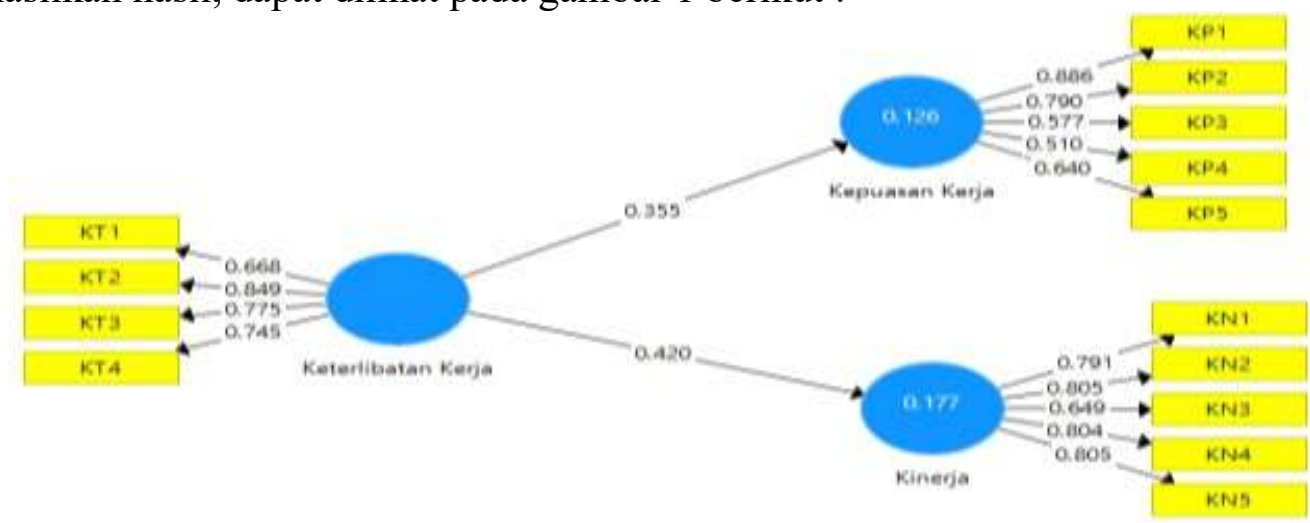

Gambar 1. Tampilan Hasil PLS Algorithm

Sehingga evaluasi hasil outer model atau model pengukuran dapat dilihat pada tabel 3 berikut:

Tabel 3. Evaluasi Model Pengukuran/Outer Model

\begin{tabular}{|c|c|c|c|c|c|c|c|}
\hline $\begin{array}{l}\text { Variabel } \\
\text { Laten }\end{array}$ & Indikator & $\begin{array}{c}\text { Outer } \\
\text { Loading }\end{array}$ & $\begin{array}{l}\text { Composite } \\
\text { Realibity }\end{array}$ & AVE & $\begin{array}{l}\text { Cronbach's } \\
\text { Alpha }\end{array}$ & $\begin{array}{c}\text { Cross } \\
\text { Loading }\end{array}$ & $\begin{array}{c}\text { Fornell } \\
\text { Larcker } \\
\text { Criterion }\end{array}$ \\
\hline $\begin{array}{l}\text { Keterlibatan } \\
\text { Kerja }\end{array}$ & $\begin{array}{l}\mathrm{KT}_{1} 1 \\
\mathrm{KT} 2 \\
\mathrm{KT} \_3 \\
\mathrm{KT}_{2} 4\end{array}$ & $\begin{array}{l}0,668 \\
0,849 \\
0,775 \\
0,745\end{array}$ & 0,846 & 0,581 & 0,762 & $\begin{array}{c}\text { Semua nilai } \\
\text { indikator } \\
\text { terhadap } \\
\text { variabelnya }> \\
\text { dari nilai }\end{array}$ & $\begin{array}{c}\text { Nilai } \\
\text { Akar } \\
\text { AVE }> \\
\text { Dari } \\
\text { Nilai }\end{array}$ \\
\hline
\end{tabular}




\begin{tabular}{|c|c|c|c|c|c|c|c|}
\hline $\begin{array}{c}\text { Variabel } \\
\text { Laten }\end{array}$ & Indikator & $\begin{array}{c}\text { Outer } \\
\text { Loading }\end{array}$ & $\begin{array}{l}\text { Composite } \\
\text { Realibity }\end{array}$ & AVE & $\begin{array}{c}\text { Cronbach's } \\
\text { Alpha }\end{array}$ & $\begin{array}{c}\text { Cross } \\
\text { Loading }\end{array}$ & $\begin{array}{l}\text { Fornell } \\
\text { Larcker } \\
\text { Criterion }\end{array}$ \\
\hline & & & & & & $\begin{array}{c}\text { indikator } \\
\text { pada variabel } \\
\text { lainnya }\end{array}$ & Korelasi \\
\hline $\begin{array}{l}\text { Kepuasan } \\
\text { Kerja }\end{array}$ & $\begin{array}{l}\mathrm{KP} \_1 \\
\mathrm{KP} \text { 2 } \\
\mathrm{KP} \_3 \\
\mathrm{KP} \_4 \\
\mathrm{KP} \_5\end{array}$ & $\begin{array}{l}0,886 \\
0,790 \\
0,577 \\
0,510 \\
0,640\end{array}$ & 0,817 & 0,508 & 0,779 & $\begin{array}{c}\text { Semua nilai } \\
\text { indikator } \\
\text { terhadap } \\
\text { variabelnya }> \\
\text { dari nilai } \\
\text { indikator } \\
\text { pada variabel } \\
\text { lainnya }\end{array}$ & $\begin{array}{c}\text { Nilai } \\
\text { Akar } \\
\text { AVE }> \\
\text { Dari } \\
\text { Nilai } \\
\text { Korelasi }\end{array}$ \\
\hline Kinerja & $\begin{array}{l}\mathrm{KN} \text { _1 } \\
\mathrm{KN} \text {-2 } \\
\mathrm{KN} \text {-3 } \\
\mathrm{KN} \text { 44 } \\
\mathrm{KN} \text { _5 }\end{array}$ & $\begin{array}{l}0,791 \\
0,805 \\
0,649 \\
0,804 \\
0,805\end{array}$ & 0,881 & 0,597 & 0,833 & $\begin{array}{c}\text { Semua nilai } \\
\text { indikator } \\
\text { terhadap } \\
\text { variabelnya }> \\
\text { dari nilai } \\
\text { indikator } \\
\text { pada variabel } \\
\text { lainnya }\end{array}$ & $\begin{array}{c}\text { Nilai } \\
\text { Akar } \\
\text { AVE }> \\
\text { Dari } \\
\text { Nilai } \\
\text { Korelasi }\end{array}$ \\
\hline
\end{tabular}

\section{Validitas Konvergen (Convergent Validity)}

Menguji convergent validity menggunakan nilai outer loadings atau loading factor. Suatu indikator dinyatakan memenuhi convergent validity dalam kategori baik apabila nilai outer loadings $\geq 0,05$. Berdasarkan tabel diatas menunjukan bahwa semua indikator sudah memiliki nilai outer loadings $\geq 0,05$ dan nilai AVE (Average Variance Extracted) untuk masing-masing indikator dinyatakan nilainya harus $\geq 0,50$ untuk model yang baik. Berdasarkan data dalam tabel diatas, diketahui bahwa nilai AVE $>0,05$.

\section{Validitas Diskriminan ( Discriminant Validity)}

Pengujian ini akan dilihat nilainya menggunakan cross loading dan Fornell Larcker Criterion. Suatu indikator dinyatakan memenuhi syarat discriminant validity apabila cross loadings indikator pada variabelnya adalah terbesar dibandingkan pada variabel lainnya dan indikator indikator menenuhi syarat discriminant validity apabila nilai fornell larcker criterion (nilai akar AVE > dari nilai korelasi).

Tabel 4. Cross Loadings

\begin{tabular}{|c|c|c|c|}
\hline $\begin{array}{c}\text { Indikator } \\
\text { Variabel }\end{array}$ & $\begin{array}{c}\text { Keterlibatan Kerja } \\
(\mathrm{X})\end{array}$ & Kinerja (Y) & $\begin{array}{c}\text { Kepuasan } \\
\text { Kerja }(\mathrm{Z})\end{array}$ \\
\hline KT1 & 0,668 & 0,270 & 0,270 \\
\hline KT2 & 0,849 & 0,394 & 0,384 \\
\hline KT3 & 0,775 & 0,318 & 0,231 \\
\hline KT4 & 0,745 & 0,267 & 0,124 \\
\hline KP1 & 0,395 & 0,280 & 0,886 \\
\hline KP2 & 0,258 & 0,334 & 0,790 \\
\hline KP3 & 0,109 & 0,284 & 0,577 \\
\hline
\end{tabular}




\begin{tabular}{|c|c|c|c|}
\hline $\begin{array}{c}\text { Indikator } \\
\text { Variabel }\end{array}$ & $\begin{array}{c}\text { Keterlibatan Kerja } \\
(\mathrm{X})\end{array}$ & Kinerja (Y) & $\begin{array}{c}\text { Kepuasan } \\
\text { Kerja }(\mathrm{Z})\end{array}$ \\
\hline KP4 & 0,016 & 0,040 & 0,510 \\
\hline KP5 & 0,115 & 0,267 & 0,640 \\
\hline KN1 & 0,299 & 0,791 & 0,312 \\
\hline KN2 & 0,349 & 0,805 & 0,306 \\
\hline KN3 & 0,196 & 0,649 & 0,195 \\
\hline KN4 & 0,351 & 0,804 & 0,316 \\
\hline KN5 & 0,382 & 0,805 & 0,284 \\
\hline
\end{tabular}

Sumber : Cross loadings untuk penelitian ini

Tabel. 5 Fornell Larcker Criterion

\begin{tabular}{|c|c|c|c|}
\hline & Keterlibatan Kerja (X) & Kinerja $(Y)$ & Kepuasan Kerja (Z) \\
\hline $\begin{array}{l}\text { Keterlibatan Kerja } \\
\text { (X) }\end{array}$ & 0,762 & & 0,355 \\
\hline $\begin{array}{l}\text { Kepuasan Kerja } \\
\text { (Y1) }\end{array}$ & & & 0,694 \\
\hline Kinerja (Y2) & 0,420 & 0,773 & 0,371 \\
\hline
\end{tabular}

Sumber : Fornell Larcker Criterion untuk penelitian

Berdasarkan hasil yang diperoleh tersebut, dapat dinyatakan bahwa variabel dan indikator yang digunakan dalam penelitian ini telah memiliki validitas diskriminan yang baik, berdasarkan syarat yang ditentukan.

\section{Reliabilitas}

Pengujian ini akan dilihat dari hasil nilai Cronbach's alpha dan composite reliability. cronbach's alpha dari masing-masing variabel penelitian harus $\geq 0,60$. Berdasarkan data pada tabel 3, dapat disimpulkan bahwa nilai cronbach's alpha dari masing-masing variabel penelitian $\geq 0,60$. Hasil ini dapat menunjukan bahwa masing-masing variabel penelitian telah memenuhi persyaratan nilai cronbch's alpha, dan reliabilitas komposit (composite reliability) untuk masing-masing indikator disyaratkan nilainya harus $\geq 0,70$ untuk model yang baik. Diketahui bahwa nilai reliabilitas komposit variabel penelitian $\geq 0,70$ berdasarkan tebel 3 menunjukan bahwa masing-masing variabel telah memenuhi Reliabilitas Komposit.

\section{Hasil Penelitian Inner Model}

Pada penelitian ini akan dijelaskan hubungan antara variabel berdasarkan nilai yang didapat dari path coefficient . Sehingga evaluasi hasil Inner Model atau Model Struktural dapat dilihat pada tabel 6 sebagai berikut :

Tabel 6. Evaluasi Model Struktural/innar model

\begin{tabular}{ccccc}
\hline Variabel laten & indicator & VIF & $\begin{array}{c}\text { Koefisien determinasi } \\
\left(\mathrm{R}^{2}\right)\end{array}$ & $\begin{array}{c}\text { Cross-validated } \\
\text { redundancy }\left(\mathrm{Q}^{2}\right.\end{array}$ \\
\hline Keterlibatan Kerja $(\mathrm{X})$ & $\mathrm{KT}$ _1 & 1,238 & & \\
& $\mathrm{KT}$ 2 & 1,608 & & \\
& $\mathrm{KT} 3$ & 1,626 & & \\
\hline
\end{tabular}




\begin{tabular}{lcccc}
\hline Variabel laten & indicator & VIF & $\begin{array}{c}\text { Koefisien determinasi } \\
\left(\mathrm{R}^{2}\right)\end{array}$ & $\begin{array}{c}\text { Cross-validated } \\
\text { redundancy }\left(\mathrm{Q}^{2)}\right.\end{array}$ \\
\hline Kepuasan Kerja (Y1) & KT_4 & 1,651 & & \\
& KP_1 & 1,482 & & 0,020 \\
& KP_2 & 1,587 & 0,126 & \\
& KP_3 & 1,451 & & \\
& KP_4 & 1,513 & & 0,097 \\
& KP_5 & 1,439 & & \\
\hline Kinerja (Y2) & KN_1 & 1,848 & & \\
& KN_2 & 1,798 & & \\
& KN_3 & 1,425 & & \\
& KN_4 & 1,819 & & \\
& KN_5 & 1,720 & & \\
\hline
\end{tabular}

Sumber : Innar Model untuk penelitian ini \

Untuk variabel kinerja pegawai nilai R-Square sebesar 0,177 yang artinya variabel keterlibatan kerja mempengaruhi variabel kinerja pegawai melalui masuk dalam kategori rendah. Dapat dikatakan kinerja pegawai di pengaruhi oleh variabel independen sebesar $17,7 \%$ sedangkan $83,3 \%$ di pengaruhi oleh variabel lain diluar variabel yang di teliti oleh peneliti. Dan untuk variable kepuasaan kerja nilai R- Square sebesar 0,126 yang artinya variable keterlibatan kerja mempengaruhi kepuasan kerja dalam kategori rendah. Dapat dikatakan kinerja dipengaruhi variable independent sebesar $12,6 \%$ sedangkan $88,4 \%$ dipengaruhi oleh variable lain diluar variabel yang diteliti oleh peneliti.

Berdasarkan perhitungan diatas nilai Prediction Relevance (Q-Square) lebih dari 0 (nol) artinya memiliki prediktif yang relevan. Untuk nilai VIF (variance inflation factor) di atas 5 menunjukan kemungkinan masalah collinearity diantara kontruksi prediktor, sehingga berdasarkan tabel 6 bahwa nilai VIF semua di bawah 3 dapat disimpulkan tidak ada masalah collinearity di antara konstruksi prediktor (Permasalahan yang dihadapi pada saat menduga koefisien model regresi linear).

\section{Uji Hipotesis}

Berdasarkan olah data yang telah dilakukan, hasilnya dapat digunakan untuk menjawab hipotesis pada penelitian ini. Uji hipotesis pada penelitian ini dilakukan dengan melihat nilai T-Statistics dan nilai P-Value. Berikut adalah hasil uji hipotesis yang diperoleh dalam penelitian ini pada tabel 7 output SmartPLS, yaitu sebagi berikut :

Tabel 7 Path Coefficient dan Specific Indirect Effects

\begin{tabular}{ccccccc}
\hline Variabel & $\begin{array}{c}\text { Sampel Asli } \\
(\mathrm{O})\end{array}$ & $\begin{array}{c}\text { Rata-rata } \\
\text { Sampel (M) }\end{array}$ & $\begin{array}{c}\text { Standar Deviasi } \\
(\text { STDEV) }\end{array}$ & $\begin{array}{c}\text { T Statistik }(\mid \\
\text { O/STDEV) }\end{array}$ & P Values & Hasil \\
\hline $\begin{array}{c}\text { Keterlibatan } \\
\text { Kerja }-> \\
\begin{array}{c}\text { Kepuasaan } \\
\text { Kerja }\end{array}\end{array}$ & 0,355 & 0,398 & 0,113 & 3,146 & $\mathbf{0 , 0 0 2}$ & Diterima \\
\hline $\begin{array}{c}\text { Keterlibatan } \\
\text { Kerja }-> \\
\text { Kinerja }\end{array}$ & 0,420 & 0,439 & 0,070 & 5,974 & $\mathbf{0 , 0 0 0}$ & Diterima \\
\hline
\end{tabular}

Sumber : Konsep Path Coefficient dan Specific Indirect Effects untuk penelitian

Penguji Hipotesis (H1)

Dalam penguji pertama ini dilakukan untuk melihat apakah keterlibatan kerja 
berpengaruh signifikan terhadap kepuasan kerja. Hasil penelitian pada tabel 7 diatas, nilai sampel asli Keterlibatan Kerja -> Kepuasan Kerja adalah 0,355 dengan signifikansi 5\% yang ditunjukan dengan nilai T- statistik 3,146>1,657 serta $\mathrm{P}$ value $0,002<0,05$. Maka dinyatakan bahwa keterlibatan kerja berpengaruh positif dan signifikan terhadap kepuasan kerja. Berdasarkan hasil tersebut dapat disimpulkan bahwa hipotesis $\mathrm{H} 1$ diterima

\section{Penguji Hipotesis (H2)}

Dalam penguji kedua ini dilakukan untuk melihat apakah keterlibatan kerja berpengaruh signifikan terhadap kinerja pegawai. Hasil penelitian pada tabel 7 diatas, nilai sampel asli Keterlibatan Kerja -> Kinerja pegawai adalah 0,420 dengan signifikansi 5\% yang ditunjukan dengan nilai T- statistik 5,974 > 1,657 serta $\mathrm{P}$ value $0,000<0,05$. Maka dinyatakan bahwa keterlibatan kerja berpengaruh positif dan signifikan terhadap kinerja pegawai. Berdasarkan hasil tersebut dapat disimpulkan bahwa hipotesis $\mathrm{H} 2$ diterima

\section{Pembahasan}

Pengaruh Keterlibatan Terhadap Kepuasan Kerja

Berdasarkan hasil pengujian hipotesis kedua, dapat disimpulkan bahwa variabel keterlibatan kerja berpengaruh positif dan signifikan terhadap kepuasan kerja. Hal ini didukung oleh pernyataan pada variabel keterlibatan kerja item pernyataan X3 yaitu "saya bertanggung jawab dengan pekerjaan yang diberikan", dengan rata-rata (mean) jawaban responden 3,70 kategori setuju dengan capaian $74 \%$.

Pegawai dengan job involvement yang tinggi akan berpartisipasi aktif terhadap pekerjaan. Individu dengan tingkat job involvement yang tinggi mengalami tingkat kepuasan yang tinggi serta mencintai pekerjaan yang dijalaninya. Sehingga dalam penelitian ini menyatakan bahwa keterlibatan kerja pada Perwakilan Kantor BKKBN Provinsi Kalimantan Tengah dapat memberikan pengaruh secara positif dan signifikan terhadap kepuasan dengan kata lain keterlibatan kerja memberikan pengaruh positif dan langsung kepada pegawai sehingga dapat meningkatkan kepuasan kerja pegawai Perwakilan BKKBN Provinsi Kalimantan Tengah.

Hasil penelitian ini sejalan dengan penelitian yang dilakukan Yakup (2017), Ariana \& Riana (2017) yang menyatakan bahwa keterlibatan kerja mempunyai pengaruh positif dan signifikan terhadap kepuasan kerja.

\section{Pengaruh Keterlibatan Kerja Terhadap Kinerja}

Berdasarkan hasil pengujian hipotesis pertama, dapat disimpulkan bahwa variabel keterlibatan kerja berpengaruh positif dan signifikan terhadap kinerja pegawai. Hal ini didukung oleh pernyataan pada variabel keterlibatan item pernyataan X4 yaitu "saya selalu berusaha menyelesaikan pekerjaan, sehingga tidak ada pekerjaan yang terhambat”, dengan rata-rata (mean) jawaban responden 3,53 kategori setuju dengan capaian 70,6\%.

Keterlibatan kerja (job involvement) adalah salah satu pendukung pegawai melakukan 
kinerja yang baik, jika pegawai ikut terlibat dalam pekerjaannya secara tidak langsung dia akan mengeluarkan ide dan pendapat terhadap pekejaannya dari itu dampaknya terhadap kinerja akan semakin baik. Karena jika pegawai terlibat dalam hal pekerjaannya secara tidak langsung mereka akan optimal dalam segala hal termasuk dalam kinerja karena pegawai tersebut merasa ikut memiliki organisasi dimana tempat dia bekerja. Sehingga dalam penelitian ini menyatakan bahwa keterlibatan kerja pada Perwakilan Kantor BKKBN Provinsi Kalimantan Tengah dapat memberikan pengaruh secara positif dan signifikan terhadap kinerja pegawai dengan kata lain keterlibatan kerja memberikan pengaruh positif dan langsung kepada pegawai sehingga dapat meningkatkan kinerja pegawai. Hasil penelitian ini sejalan dengan penelitian yang dilakukan Septiadi,dkk (2017), Alfajri (2019) yang menyatakan bahwa keterlibatan kerja mempunyai pengaruh positif dan signifikan terhadap kinerja.

\section{Keterbatasan Penelitian}

Pada penelitian ini penulis telah mengusahakan sesuai dengan prosedur ilmiah, namun demikian tentunya masih memiliki keterbatasan, yaitu, nilai R square (R2) dari penelitian ini sebesar 34,3\%. Peneliti berikutnya diharapkan mampu menambahkan variabel yang ada pada variabel independent; kurangnya penulis mendapatkan data yang lengkap untuk mendukung fenomena masalah yang terjadi; ada banyak faktor yang mempengaruhi kinerja pegawai ,namun peneliti hanya mengambil 2 faktor yaitu keterlibatan kerja dan kepuasan kerja; dan berdasarkan data yang terkumpul dari responden peneliti kebanyakan memilih cenderung netral/bias sehingga mengurangi banyaknya informasi yang dapat dijaring para responden

\section{KESIMPULAN DAN SARAN}

Setelah melakukan analisis mengenai pengaruh keterlibatan kerja terhadap kepuasan kerja dan kinerja pegawai pada Perwakilan Badan Kependudukan dan Keluarga Berencana Nasional (BKKBN) Provinsi Kalimantan Tengah, maka dalam kesempatan ini penulis menyimpulkan, keterlibatan kerja (X) berpengaruh positif dan signifikan terhadap kepuasan kerja (Y1) pada Perwakilan Badan Kependudukan dan Keluarga Berencana Nasional (BKKBN) Provinsi Kalimantan Tengah dan keterlibatan kerja (X) berpengaruh positif dan signifikan terhadap kinerja (Y2) pada Perwakilan Badan Kependudukan dan Keluarga Berencana Nasional (BKKBN) Provinsi Kalimantan Tengah.

Berdasarkan hasil penelitian yang telah dilakukan, maka peneliti memberi saran bagi Perwakilan BKKBN Provinsi Kalimantan Tengah, yaitu : berkaitan dengan keterlibatan kerja disarankan agar instansi perwakilan BKKBN Provinsi Kalimantan Tengah sebaiknya menempatkan pekerjaan pegawai sesuai dengan kemampuannya, supaya pegawai dapat aktif dalam bekerja; berkaitan dengan kinerja disarankan agar pegawai perwakilan BKKBN Provinsi Kalimantan Tengah dapat meningkatkan kualitas kerjanya agar tingkat pencapaian kerja yang hasilkan sesuai dengan harapan instansi (Perwakilan Badan BKKBN Provinsi Kalimantan Tengah). Untuk instansi Perwakilan BKKBN harus memperhatikan pekerjaan pegawainya apakah selesai tepat waktu, dan atasan harus lebih peduli terhadap bawahannya agar terwujudnya hubungan baik antara atasan dan bawahan; berkaitan dengan kepuasan kerja disarankan lebih memperhatikan terkait kesempatan dalam promosi jabatan kepada pegawai sesuai dengan syarat yang ada di Perwakilan BKKBN Provinsi Kalimantan Tengah sehingga dapat menghasilkan kinerja yang baik; berkaitan dengan banyaknya responden peneliti cenderung memilih netral/bias sehingga mengurangi banyaknya informasi yang dapat dijaring para responden, maka untuk peneliti selanjutnya dapat menggunakan skala liket genap tujuannya menghindari banyak responden memilih netral/ragu-ragu; bagi peneliti selanjutnya, 
hasil penelitian ini dapat dijadikan referensi mengenai pembahasan yang berkaitan dengan keterlibatan kerja (job involvement), kepuasan kerja dan kinerja pegawai; bagi peneliti selanjutnya, disarankan dapat menambah variable independen seperti variable lingkungan kerja dan komunikasi organisasi yang menurut peneliti memiliki pengaruh besar terhadap kinerja.

\section{DAFTAR PUSTAKA}

Abdullah. (2015). Metodologi Penelitian Kuantitatif. Yogyakarta: Aswaja Pressindo.

Adha, S., Wandi, D., \& Susanto, Y. (2019). Pengaruh Kepuasan Kerja Terhadap Kinerja Pegawai Pada Dinas Perindustrian, Perdagangan Dan Esdm Kabupaten Pandeglang. Jurnal Ekonomi Vokasi, 2(1), 61-72.

Alfajri, O. (2019). Pengaruh Keterlibatan Kerja Dan Stres Kerja Terhadap Kinerja Karyawan Pada PT. PLN (persero) Distribusi Jawa Timur Area Surabaya Utara. Jurnal Ilmu Manajemen (JIM), 7(2).

Arda, M. (2017). Pengaruh Kepuasan Kerja Dan Disiplin Kerja Terhadap Kinerja Karyawan Pada Bank Rakyat Indonesia Cabang Putri Hijau Medan. Jurnal Ilmiah Manajemen Dan Bisnis, 18(1), 45-60.

Ariana, I. W. J., \& Riana, I. G. (2016). Pengaruh work-family conflict, keterlibatan kerja dan stres kerja terhadap kepuasan kerja karyawan. E-Jurnal Manajemen, 5(7).

Azwina, D., \& Shahnaz, Y. (2020). Pengaruh Komunikasi Organisasi Terhadap Kinerja Karyawan Pada Pt Gapa Citra Mandiri Radio Dalam Jakarta Selatan. Jurnal Disrupsi Bisnis: Jurnal Ilmiah Prodi Manajemen, Fakultas Ekonomi, Universitas Pamulang, $3(1)$.

Azzahra, F., \& Maryati, T. (2016). Dampak Job Involvement Dalam Peningkatan Kinerja Pegawai Melalui Komitmen Organisasional (Studi Pada Kantor Badan Perencanaan Pembangunan Daerah Provinsi Daerah Istimewa Yogyakarta) . JBTI : Jurnal Bisnis: Teori dan Implementasi, 7(2), 301-324.

Dewi, I.S. (2015). Pengaruh Kepuasan Dan Lingkungan Kerja Terhadap Kinerja Karyawan Dengan Perilaku Kewargaan Organisasional Sebagai Variabel Intervening (Studi Pada Karyawan Pt Indonesian Knitting Factory Semarang). Skripsi. Universitas Negeri Semarang

Ghozali. dan Latan. (2015). Partial Least Squares: Konsep, Teknik dan Aplikasi Menggunakan Program SmartPLS 3.0. Semarang: Badan Penerbit UNDIP.

Gopinath, R., \& Kalpana, R. (2020). Relationship of job involvement with Job Satisfaction. Adalya Journal, 9(7), 306-315.

Govender, S \& SB Parumasur (2010). The Relationship between Motivation and Job Involvement. SAJEMS NS, 13 (3), 237-253.

Hamali, A. Y. (2016). Pemahaman Manajemen Sumber Daya Manusia Strategi Mengelola Karyawan .Yogyakarta: CAPS ( Center for Academic Publishing Service).

Hamid, R. S. \& Anwar S. M. (2019). Structural Equation Modeling (Sem) Berbasis Varian: Konsep Dasar dan Aplikasi dengan Program SmartPLS 3.2.8 dalam Riset Bisnis. Jakarta: PT Inkubator Penulis Indonesia 
Hussein, A.S. (2015) Penelitian Bisnis dan Manajemen Menggunakan Partial Least Squares (PLS) dengan smartPLS 3.0, (Universitas Brawijaya: Modul Ajar)

Kasmir. (2019). Manajemen Sumber Daya Manusia (Teori dan Praktek). Depok: PT. Raja Grafindo Persada.

Khan, K., \& Nemati, A. R. 2011. Impact of Job involvement on employee satisfaction : A study based on medical doctors working at Riphah International University Teaching Hospitals in Pakistan. African Journal of Business Management, 5(6), 2241-2246.

Latan, H \& Temalagi, S. (2013). Analisis Multivariate Teknik dan Aplikasi Menggunakan Program IBM SPSS 20.0. Bandung : Alfabeta.

Luthans, Fred. (2011). Organizational Behavior An Evidence-Based Approach. Twelth Edition. New York: McGraw-Hill/Irwin.

Mathis, R.L., \& Jackson, J.H. (2011). Manajemen Sumber Daya Manusia. Jakarta: Salemba Empat

Mangkunegara, A.A. Anwar Prabu. (2015). Manajemen Sumber Daya Manusia Perusahaan. Bandung: PT Remaja Rosdakarya.

Nurjayadi, R. D. (2005). Kepuasan Kerja pada Karyawan Ditinjau Berdasarkan Faktor Demografik dan Motif Berprestasi. Psikologika: Jurnal Pemikiran dan Penelitian Psikologi, 10(19), 50-57.

Prasetyo, B \& Jannah, L. M. (2011). Metode Penelitian Kuantitatif, Teori dan Aplikasi. Jakarta : RajaGrafindo.

Robbins, S.P. and Judge, T. A. (2012). Perilaku Organisasi Edisi 12. Jakarta : Salemba Empat

Robbins, S.P., M. Coulter. (2010). Management. Edisi Kesepuluh, Jilid 2. Jakarta: Penerbit Erlangga.

Romahdona, J. R. (2017). Pengaruh Work-Life Balance Dan Job Involvement Pada In-Role Performance Dengan Affective Commitment Sebagai Variabel Mediasi (Studi pada Karyawan Perempuan bagian Cantel dan Gunting PT Interwork Indonesia di Purbalingga). Doctoral dissertation, Universitas Negeri Semarang.

Safaniah. (2001). Metodelogi Penelitian. Jakarta. Penerbit Erlangga.

Said, Muhammad Maseud. (2011). Kepemimpinan: Pengembangan Organisasi Team Building Dan Perilaku Inovatif. Malang: UIN-Maliki Press.

Septiadi, S. A., Sintaasih, D. K., \& Wibawa, I. M. A. (2017). Pengaruh keterlibatan kerja terhadap kinerja dengan pemediasi komitmen organisasional. E-Jurnal Ekonomi dan Bisnis Universitas Udayana, 6(8), 3103-3132.

Silen, A. P. (2016). Pengaruh Modal Psikologi Dan Keterlibatan Pegawai Terhadap Kinerja Pegawai Dengan Kepuasan Kerja Sebagai Variabel Mediasi (Studi Pegawai Politeknik Ilmu Pelayaran Semarang). Jurnal Manajemen Teori dan Terapan| Journal of Theory and Applied Management, 9(3).

Siregar. (2012). Metodelogi Penelitian. Jakarta. Penerbit Erlangga.

Sitinjak, L. N. (2018). Pengaruh Lingkungan Kerja Terhadap Kepuasan Kerja Karyawan (Studi pada Karyawan PT. Mitra Pinasthika Mustika Rent Tangerang Selatan). Jurnal Administrasi Bisnis, 60(2), 162-168. 
Sofyan Sieregar. (2013). Metodelogi Penelitian. Jakarta. Penerbit Erlangga.

Sugiyono . (2014). Metode Penelitian Bisnis. Bandung: Alfabeta.

Sugiyono. (2011). Statistik untuk Pendidikan. Bandung: Penerbit Alfabeta,

Sugiyono. (2004). Metode Penelitian. Jakarta: Penerbit Suci Pres.

Sugiyono. (2015). Metode Penelitian. Jakarta: Penerbit Suci Pres.

Sutrisno. (2016) Sutrisno, Edy. 2013. Manajemen Sumber Daya Manusia, Edisi Pertama, Jakarta : Kencana.

Sutrisno, Edy. (2019). Manajemen Sumber Daya Manusia. Jakarta : Prenamedia Group.

Suyadi. (1997). Manajemen Sumber Daya Manusia untuk Perusahaan. Jakarta: PT. Raja Grafindo Persada.

Thevanes, N., \& Dirojan, T. (2018). Impact of training and job involvement on job performance. International Journal of Scientific and Management Research, 1(1), 1-10.

Thoha, (2005). Perilaku Organisasi: Konsep Dasar dan Aplikasinya. Jakarta: Raja Grafindo Persada

Umam, Khaerul. (2010). Perilaku Organisasi. Bandung: CV Pustaka Setia.

Uno, Hamzah B. (2009). Teori motivasi dan Pengukurannya (Analisis di Bidang Pendidikan). Jakarta : Bumi Aksara

Wahyudi, W. D., \& Tupti, Z. (2019). Pengaruh Budaya Organisasi, Motivasi dan Kepuasan Kerja Terhadap Kinerja Pegawai. Maneggio: Jurnal Ilmiah Magister Manajemen, 2(1), $31-44$.

Wibowo. (2017). Manajemen Kinerja. Edisi Kelima. Depok: Rajagrafindo Persada.

Wijaya, Candra. (2017). Perilaku Organisasi. Medan: Lembaga Peduli Pengembangan Pendidikan Indonesia.

Wikipedia. Badan Kependudukan dan Keluarga Berencana Nasional. Melalui https://id.wikipedia.org/wiki/Badan_Kependudukan_dan_Keluarga_

Berencana_Nasional.[03/10/2020]

Wirawan. (2015). Evaluasi Kinerja Sumber Daya Manusia (Teori, Aplikasi, dan Penelitian). Jakarta: Salemba Empat.

Wuarlima, F., Kojo, C., \& Sendow, G. M. (2019). Pengaruh Keseimbangan Kehidupan Kerja, Keterlibatan Kerja Dan Pengembangan Karir Terhadap Kepuasan Kerja Karyawan Pada Gran Puri Hotel Manado. Jurnal EMBA: Jurnal Riset Ekonomi, Manajemen, Bisnis dan Akuntansi, 7(4).

Yakup, Y. (2017). Pengaruh keterlibatan kerja, budaya organisasi dan motivasi kerja terhadap kepuasan kerja pegawai. Perisai: Islamic Banking and Finance Journal, 1(3), 273-290

Yeh, C. M. (2013). Tourism involvement, work engagement and job satisfactio among frontline hotel employees. Annals of Tourism Research, 42, 214-239. 